\title{
THE IMPACTS OF UNDEREMPLOYMENT AND CAREERISM ON ORGANIZATIONAL TRUST AND CREATIVITY: THE MODERATING ROLES OF PERSONALITY AND ORGANIZATIONAL COLLECTIVISM
}

\author{
DOI: 10.17261/Pressacademia.2019.1159 \\ RJBM- V.6-ISS.4-2019(6)-p.291-305
}

\section{Ibrahim Bouzidani ${ }^{1}$, Alev Torun ${ }^{2}$}

${ }^{1}$ Marmara University, Department of Organizational Behavior, Istanbul, Turkey. ibrahimbouzidani@marun.edu.tr, ORCID: 0000-0003-3585-9352

${ }^{2}$ Marmara University, Department of Organizational Behavior, Istanbul, Turkey. atorun@marmara.edu.tr, ORCID: 0000-0002-4205-4176

Date Received: October 10, 2019

Date Accepted: December 21, 2019

\section{To cite this document}

Bouzidani, I, and Torun, A. (2019). The impacts of underemployment and careerism on organizational trust and creativity: the moderating roles of personality and organizational collectivism. Research Journal of Business and Management (RJBM), V.6(4), p.291-305

Permemant link to this document: http://doi.org/10.17261/Pressacademia.2019.1159

Copyright: Published by PressAcademia and limited licenced re-use rights only.

\begin{abstract}
Purpose- The present study aimed to explore the contributions of underemployment and careerism to organizational trust and creativity; and to examine the moderating effects of agreeableness, openness to experience, and organizational collectivism on these relationships.

Methodology- The study was conducted in the province of Istanbul/Turkey, among a convenient sample of 156 participants from private organizations. For testing the hypotheses of the present study, simple regression and multiple regression analyses were utilized.

Findings- All underemployment and careerism dimensions were interrelated. Besides, the two dimensions of underemployment were found to be significantly related to the two dimensions of creativity. Also, underemployment and organizational trust, on the one hand, and careerism and creativity, on the other hand, displayed significant relationships. The moderating role was only found for agreeableness on the relationship between behavioral careerism and trust in supervisors.

Conclusion- The impacts of underemployment and careerism on creativity and organizational trust need to be explored further. In addition to that, the moderating roles of other personality traits on these relationships need to be looked at as well.
\end{abstract}

Keywords: Underemployment, careerism, organizational trust, creativity, moderators.

JEL Codes: B30, O31, M14

\section{INTRODUCTION}

It is believed that the traditional Weberian approach of a career which is about the involvement of an employee in a long-term relationship with an organization no longer fits the new epoch career system. The new era is pushing forward to transform the traditional employment relationship from a relational to a more transactional psychological contract, where guaranteed employment will be replaced by short-term arrangements and positions (Adams, Srivastava, Herriot, and Patterson, 2012; Sullivan and Baruch, 2009). All these changes are automatically confronted with new attitudes and behavioral coping strategies by employees; for instance, the perception of underemployment and careerism orientation (Adams, et al., 2012). Underemployment and careerism, which are to a large extent human-made psycho-social phenomena, are being considered as negative factors in the workplace. However, the fact that these phenomena are a natural reaction to the new situation imposed on the workforce in modern societies is ignored. As a result of this negative view, many researchers have conducted studies to explore the negative consequences of these two variables on employees and organizations (Feldman \& Weitz, 1991; Rousseau, 1990).

Unlike previous studies, this research sought to uncover potential positive effects by looking into the positive side of underemployment and careerism. They may be related to positive consequences such as creativity. Based on Meyer, Allen, and Smith's (1993) Model of Organizational Commitment (MOC) and the work of Zhou and George (2001), this study argues that 
underemployed employees could be beneficial for their organizations. ${ }^{1}$ According to the MOC, dissatisfied employees may be creative in terms of finding new ways of solving problems in case they face any challenges because they are overqualified for the job that they are doing (Zhou and George, 2003). The same opinion may be asserted concerning careerism. Employees who are careerism-oriented may be very creative since they have different work experiences in different jobs and organizations. Besides, they are vivid, open to new experiences, and boundaryless in terms of their tasks and working scope (Amabile, 1983; MacKinnon, 1962). Additionally, the present study has put forward another claim based on Amabile's (1983) Componential Theory of Creativity. According to her, any creative process should be initiated through internal motives, and generally, the main sources of these inner motives are the environmental and personal variables which guide employees. Therefore, and by following Amabile's (1983) theory, it is suggested that collectivism as a contextual variable and openness to experience as a personal variable will be considered as moderators that would strengthen the positive effects of underemployment and careerism on creativity.

Careerism and underemployment are also expected to be related to the organizational trust. The relationship between these variables is another issue searched in this study. Very few studies have examined these relationships, and they have reported negative results in terms of the trust. For instance, Crawshaw and Brodbeck (2011) have found that employees' careerist orientations were negatively related to perceptions of trust in their supervisors. Also, Feldman, Leana, and Bolino (2002) have suggested that underemployment may lead to negative job attitudes and job behaviors. Very few researchers have tackled this topic up to now and this study aims to fill the gap in the literature. To examine if the suggested relationships will be affected by individual and contextual variables, firstly it is argued that the trust of an employee who is careerism-oriented might be affected less negatively if he/she has an agreeable type of personality. Since agreeable people are more likely to confide in others, it is assumed that agreeableness could be a moderator which might weaken the relationship between careerism and organizational trust. Secondly, it is assumed also and based on Beck's (1999) theory that, an organizational culture of the collectivist type could moderate the relationship between underemployment and organizational trust. It is expected that the solidarity between organizational members may decrease the negative effect of feeling underemployed over the trust in others.

In the following paragraphs, the literature review regarding the previous variables will be mentioned and discussed. In addition to that, the hypotheses of the study will be formulated upon that.

\section{LITERATURE REVIEW}

\subsection{The Relationship between Underemployment and Careerism}

According to Feldman et al. (2002) and Cockroft (2011), underemployment is an antecedent of careerism, and they have explained this phenomenon as a state of frustration. The employee feels that he/she is not able to fully use his/her skills, becomes pessimistic about his/her work conditions, and increasingly starts developing the belief that the success in work has nothing to do with the objective performance but it is all about nonperformance activities such as networking, self-presentation strategies, and so on. Building on Feldman et al's (2002) study, Cockroft (2011) conducted another study to explore the nature of the relationship

\footnotetext{
${ }^{1}$ Since the present article aims to study the effects of underemployment and careerism on creativity and organizational trust from one side, and the moderating role of openness to experience, agreeableness, and organizational collectivism on these relationships form the other side, several theories and models have been used to formulate the theoretical framework of the present study. Firstly, Beck's (1999) Risk Society Theory (RST) was used to explain how the present socio-economic developments created a new era that is pushing forward a more transactional psychological contract, where guaranteed employment will be replaced by short-term arrangements and positions. The conditions may result in more underemployed employees, which in turn lead to distrust between employees and employers, in a more individualistic environment. Therefore, Beck's (1999) theory was used to justify the impact of underemployment on organizational trust and the moderating role of organizational collectivism in this relationship. Secondly, Amabile's (1983) Componential Theory of Creativity (CTC) was utilized to give grounds for the moderating role of organizational collectivism as a contextual variable and openness to experience as a personal variable on the effects of underemployment and careerism on creativity. This is based on CTC's claims that any creative process should be initiated through internal motives, and generally, the main sources of these inner motives are the environmental and personal variables that guide employees. Lastly, Meyer, Allen, and Smith's (1993) Model of Organizational Commitment (MOC) is used. Based on the MOC, the dissatisfied employees -who are underemployed and careerism oriented- may be creative in terms of finding new ways of solving problems in case they face any challenges because they are overqualified for the job that they are doing. Thus, based on the previous theories and models, in addition to some other studies, the theoretical framework of the present study was formulated.
} 
between underemployment and careerism. Cockroft (2011) found that skills, job mismatch, and pay dimensions of underemployment were significantly correlated with careerism; whereas he found other two dimensions of underemployment which are involuntary part-time work and involuntary temporary work not to be significantly correlated with the construct. The researcher explained the findings of his study as follows: employees who experienced lack of skill exploitation or who perceived inconsistency between their educational level and payment, or a mismatch between their educational level and the job which they are doing, generally displayed a strong careerism orientation. Besides, it may also be possible that employees who display careerist inclinations and believe that climbing the career ladder is not solely based on merit may be more likely to perceive their employment status as inadequate. Therefore, the following hypothesis is formulated:

H1: Underemployment will be positively related to careerism.

\subsection{The Impacts of Underemployment on Creativity and Organizational Trust}

Feldman et al. (2002) have suggested that underemployment may lead to negative job attitudes and job behaviors. According to them, laid-off and re-employed workers both desire and feel it is their right to have better jobs than those they occupy at this point in their careers. In turn, this desire for, and feeling of the prerogative to, better occupations and professions may straightforwardly lead to more negative work attitudes. As it can be noticed, Feldman (1996) has mentioned about job attitudes and job behaviors in general without specifying any. Some examples of important job attitudes and behaviors in the workplace are creativity and trust. In a study, Lin, Law, and Zhou (2017) attempted to explore the positive contributions of underemployment on creativity and organizational citizenship behavior. Lin et al. (2017) have found that underemployment could be a positive element in the workplace, and an underemployed employee could be a creative person if the organization fulfills some conditions.

The relationship between underemployment and organizational trust was a part of Beck's (1999) The Risk Society Theory. According to him, the socio-economic development of the world could be divided into three stages: the pre-modern societies, the early-simple modern societies, and the reflexive modernity. The last stage of these social developments started later in the 20th century. Beck (1999), asserts that, in this stage, individuals generally, consider themselves as the center of the eco-social activities. The author suggests that reflexive modernity expresses two important ideas: firstly, for the individuals, it is a stage that made them reconsider their relationship with and loyalty to the institutions which they are tied to; secondly, for the society, it is a period of the negative reflexivity of the modern society, which reflects its hideous face. According to the researcher, everything is becoming harmful and a source of hazard for the individual and his/her environment.

Consequently, and based on the earlier studies, it is hypothesized that:

H2: Underemployment will have a positive contribution to creativity.

H3: Underemployment will have a negative contribution to organizational trust.

\subsection{The Impacts of Careerism on Creativity and Organizational Trust}

A contradictory relationship exists relating to the nature of careerism and its outcomes. Generally, researchers have put forward negative assumptions about the outcomes of careerism (Feldman and Weitz 1991); however, there are other perspectives which convey that careerism may bring about some positive outcomes. The previous claim could be supported by Greenhaus, Callanan, and DiRenzo's (2008) study which revealed that careerism-oriented employees had been commonly characterized as being highly adaptive and flexible. The positive side of careerism stands on Rousseau's (1990) point of view. She argued that careerism is a concept which has so much overlapped with two concepts, protean career, and boundaryless career. Protean career reflects the person who is self-directed and internally driven by his/her convictions. Boundaryless career, on the other hand, reflects the person who sees himself/herself and his/her career as being independent of organizational boundaries. The individual may work in different organizations to do different jobs since he/she has acquired many skills and experiences (Adams et al., 2012; Arthur and Rousseau, 1996; Briscoe, Hall, and DeMuth, 2006). Therefore, it may be assumed that individuals with such a nature may be expected to display creative activity at work.

Not only the relationship between careerism and creativity seems misty, but the relationship between careerism and trust also involves the same ambiguity. The only study which has been found in this context is that of Crawshaw and Brodbeck (2011). In this study, the researchers aimed to explore the antecedents of careerist orientations to work. They hypothesized that employee perceptions of trust in management are negatively related to their careerist orientations to work. In this study, Crawshaw and Brodbeck (2011) explained the negative relationship between careerism and trust in such a way that employees' mistrustful attitudes towards management may lead to the perception that their career development opportunities are allocated inequitably. 
The other way round may also be possible, and it may be proposed that employees with careerist intentions would be likely to develop distrust at work.

So, based on the previous studies it will be assumed that:

H4: Careerism will have a positive contribution to creativity.

H5: Careerism will have a negative contribution to organizational trust.

\subsection{Moderating Effects of Organizational Collectivism, Openness to Experience, and Agreeableness}

In the following paragraphs, the discussion will be upon the literature related to the moderating roles of organizational collectivism, openness to experience, and agreeableness on the main variables of the study:

\subsubsection{The Moderating Effects of Organizational Collectivism and Openness to Experience on the Impacts of Underemployment and Careerism on Creativity}

In this study, it is assumed that underemployment and careerism will display positive relationships with creativity. When employees feel underemployed and develop careerist tendencies, supportive contextual characteristics such as cooperation at work, and their personality characteristics such as innovativeness may increase the positive effects of these factors on creativity.

Based on Amabile's (1983) componential theory of creativity, researchers have emphasized the fact that the personal and contextual characteristics contribute jointly to creativity (Oldham and Cummings, 1996). The studies revealed that for an employee to be creative in his/her performance, he/she has to be intrinsically motivated, which means, he/she feels excited and interested in engaging in his/her work activities willingly, and for the sake of the work itself. For instance, the personality traits of an employee could be a great source for enhancing and applying his/her creative skills and abilities (Oldham and Cummings, 1996).

Some researchers confirmed the significance of personality traits in terms of their relationship and predictability to creativity, yet mixed results have been found regarding these relationships; the status that has led some scholars to admit the fact that, personality traits are domain-general, which means the effects of a personality trait might change based on the conditions. In a meta-analytical study, researchers have found that three personality traits, namely, openness to experience, extraversion, and neuroticism were positively related to creativity, whereas, agreeableness and conscientiousness were found to be negatively related (Feist, 1998; Batey and Furnham, 2006). Therefore, an employee who is careerism-oriented might be very creative if he/she displays openness to experience as a type of personality.

However, the original initiator of an employee's intrinsic motivation comes from the organizational context or the work environment. The notion that the supportive social context could be a real incentive for a creative environment in the workplace has been referred to in several previous studies (Amabile, Conti, Coon, Lazenby, and Herron, 1996; Oldham and Cummings, 1996; Zhou and George, 2001). The elements of the organizational context are organizational and supervisory encouragement, workgroup support, freedom, sufficient resources, challenging work, workload pressure, and organizational impediments (Amabile et al., 1996).

Based on the above studies and assumptions, it will be hypothesized that:

H6: Organizational collectivism will strengthen the positive relationship between underemployment and creativity.

H7: Openness to experience will strengthen the positive relationship between careerism and creativity.

\subsubsection{The Moderating Effects of Organizational Collectivism and Agreeableness on the Impacts of Underemployment and Careerism on Organizational Trust}

In this study, it is assumed that underemployment and careerism will display negative relationships with organizational trust. When employees experience underemployment and careerism; solidarity at work and an amenable personality may decrease the negative effects of these factors on organizational trust.

According to Beck (1999), underemployment has been considered to be among the five elements that characterize the world risk society; these five interrelated elements are globalization, individualization, gender revolution, underemployment, and global risks (e.g. ecological crisis and the crash of global financial markets). For Chan (2012), these elements operate within an integrated format. As it was discussed previously, one of the natural results of the reflexive modernity era and the interactive effects of the 
five factors that generate the risk society is the distrust that will be a common attitude among people and their institutions. Therefore, and based on the preceding explanation, an employee who is underemployed, most probably experiences distrust in his/her workplace, and the distrust will be strengthened if the environment which he/she is working within is individualisticoriented. So, in a reverse sense, it could be assumed that the distrust attitude will be weakened if the same employee works in a collectivist-oriented environment.

The moderating role of agreeableness on the relationship between careerism and trust, on the other hand, could be explained by the conditional effects of personality characteristics. The trust between a careerism-oriented employee and his/her organization and supervisors will be negative; however, if this particular employee has an agreeable type of personality, this negative relationship might be weakened. This is because an employee who is characterized as agreeable is generally described to be forgiving and trusting in nature (Caliendo, Fossen, and Kritikos, 2014).

One of the theories which explain how trust is formed is the personal innate predisposition view. In this approach, trust depends largely on the trustor's innate propensity to trust. Trust is therefore conceived as a stable predisposition that does not change over time and is closely related to personality traits (Uslaner, 2002). The studies which targeted the relationship between FFM (Five-Factor Model) of personality traits and trust revealed mixed results, which certainly merit a closer look before passing judgment (Freitag and Bauer, 2016). For instance, in a study, trust was found to have a significant relationship with agreeableness only (Mondak and Halperin, 2008). In another study, all personality traits were significantly related to trust (Dinesen, et al., 2014). In other studies, personality traits were found to have a significant relationship with some dimensions of organizational trust only. For example, Freitag and Bauer (2016) have found that conscientiousness and openness are significantly related to trust for coworkers and strangers; whereas agreeableness was more related to trust in strangers only.

Therefore, the following hypotheses are formulated:

H8: Organizational collectivism will weaken the negative relationship between underemployment and organizational trust.

H9: Agreeableness will weaken the negative relationship between careerism and organizational trust.

Based on the previous studies and literature, the model of this study is formulated as illustrated in Figure 1.

Figure 1: The Conceptual Research Model

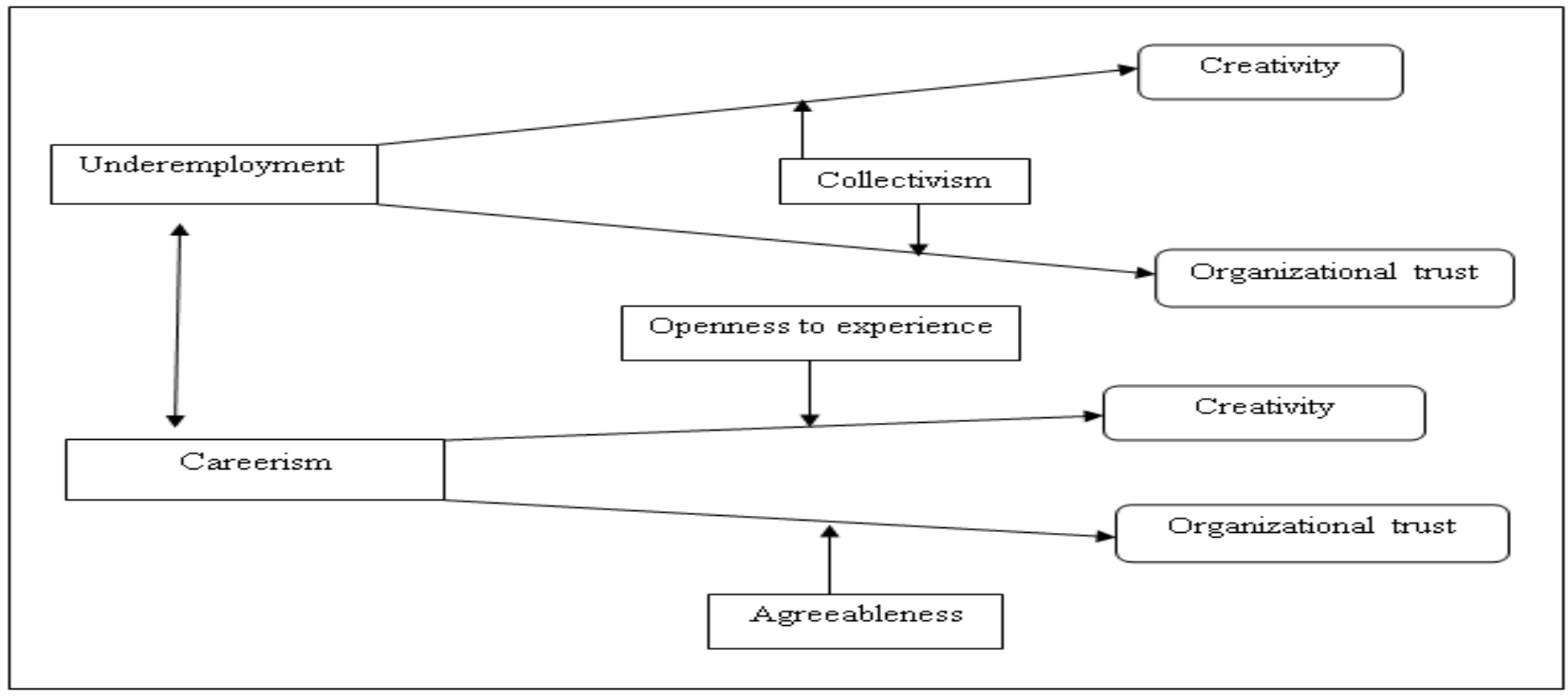

\section{DATA AND METHODOLOGY}




\subsection{Participants and Procedure}

In the present study, it was aimed to explore the constructs of underemployment and careerism among employees working in private organizations. The study was conducted in the province of istanbul/Turkey, among a convenient sample of 156 participants. They occupied positions as technicians, officers, experts, middle-level managers, and upper-level managers in the private sector. The sample of the study consists of 112 males ( $71.8 \%)$ and 44 females $(28.2 \%)$. The age range was between 18 and 72 . The majority of the participants were university graduates ( 76 respondents forming $48.7 \%$ of the sample). More than half of the participants ( 87 respondents forming $55.8 \%$ of the sample) worked for less than five years in the present workplace.

The respondents were approached by both in a face to face fashion and via delivering e-mails and Google Forms (an online version of the questionnaire). The time to complete the questionnaire was approximately 15 minutes. The participants were given information that the responses will be kept confidentially.

\subsection{Instruments}

The data was collected through several scales. The first scale was a (7) seven-item questionnaire, used to gather the demographic data. In measures, 2 to 7, the responses were expressed on a 1 to 6 scale ranging from (1) strongly disagree to (6) strongly agree. Higher scores indicated a higher level of the measured construct.

The second instrument was an (8) eight-item scale, used to measure careerism, the perception of an employee about how to move up the career ladder. The scale consists of items drawn from two separate careerism measuring scales; the five-item scale developed by Rousseau (2000) $(\alpha=0.77)$, and the five-item scale developed by Chay and Aryee (1999) $(\alpha=0.68)$, which in itself was a shortened version of an earlier scale developed by Feldman and Weitz (1991) that included 23 items.

The third one was a (13) thirteen-item scale used to measure underemployment. The measure was developed by Bolino and Feldman (2000) ( $\alpha=0.90)$ to assess skill utilization and underemployment. The items tapped into the extent to which individuals' work was not challenging, did not provide learning opportunities, and did not fully utilize their education, experience, training, skills, and abilities (Bolino and Feldman, 2000).

The fourth scale was utilized to measure organizational trust, a (12) twelve-item subscale. The scale was developed by Nyhan and Marlowe (1997) ( $\alpha=0.89)$. The scale is mainly built upon Luhmann's (1979) Systems Theory. Based on his view, trust is considered as a multi-dimensional construct, containing two dimensions: personal and systems trust, or trust in supervisors and trust in the organization. Therefore, Nyhan and Marlowe (1997) have constructed their OTI with twelve items; eight items measuring trust in supervisors and four items measuring trust in the organization.

The fifth instrument was a (7) seven-item scale, used to measure organizational collectivism. The scale was developed by Robert and Wasti (2002) $(\alpha=0.81)$ to explore the extent to which employees perceived the organizational culture as focused on group priority.

The sixth measure was a (13) thirteen-item scale utilized to collect data about creativity. The scale was developed by Zhou and George (2003) ( $\alpha=0.94)$. It was constructed based on the creativity conceptualization of Amabile (1998) to reveal the extent to which individuals are capable of novel thinking.

The seventh and last tool was used to measure openness to experience and agreeableness. The two of the five factors of the TenItem Personality Inventory (TIPI), namely, Openness to Experience $(\alpha=0.45)$ and Agreeableness $(\alpha=0.40)$ were used in this study. TIPI was developed by Gosling, Rentfrow, and Swann (2003). The scale assesses personality using the Big Five Model (Five-Factor Model). It contains ten items, each pair of items measuring one of the five factors which are: Extraversion, Agreeableness, Conscientiousness, Emotional Stability, and Openness to Experience. In the present study, all items of openness to experience and agreeableness are worded in a positive direction.

\section{RESULTS}

\subsection{The Validity and Reliability of the Measures}

The internal consistency analyses and factor analyses were performed for all the scales that were used in this study, using Cronbach's alpha coefficient and principal components analysis technique. Throughout the process, the following common criteria were taken into consideration: 1- Coefficients of Cronbach alpha close to .60 (if the number of the items is less than 10) and above were considered as adequate for internal consistency, 2 - an item that had a factor loading of less than 0.40 was eradicated, 3 - in 
case an item was loaded on two or more factors with a .10 or less difference, that item was deleted, 4- also, if only one item was loaded on a factor, that item was deleted (Loewenthal, 2001).

The results of the rotated component matrix revealed that the careerism scale has two factors which are: attitudinal careerism and behavioral careerism. The total variance explained by these factors is $52.44 \%$ (KMO=0.73; Bartlett's Test of Sphericity $X^{2}: 265.51$; df: 28; $\left.\mathrm{p}<0.001\right)$. Also, underemployment was found to reveal two dimensions: skill utilization and learning opportunities. The total variance explained by these factors is $65.15 \%$ (KMO=0.84; Bartlett's Test of Sphericity $X^{2}: 822.09$; df: 45 ; $\mathrm{p}<0.001)$. Personality, as expected, displayed two dimensions: openness to experience and agreeableness. The total variance explained by these factors is $78.22 \%$ (KMO=0.60; Bartlett's Test of Sphericity $X^{2}: 136.37$; df: 6 ; p<0.001). Organizational collectivism, on the other hand, appeared as a unidimensional variable. The total variance explained by this factor is $66.29 \%$ (KMO=0.87; Bartlett's Test of Sphericity $X^{2}: 761.59$; df: $\left.21 ; \mathrm{p}<0.001\right)$. Organizational trust yielded two dimensions: trust in supervisors and trust in the organization. The total variance explained by these factors is $69.42 \%$ (KMO=0.88; Bartlett's Test of Sphericity $\left.X^{2}: 1456.04 ; \mathrm{df}: 66 ; \mathrm{p}<0.001\right)$. Similarly, creativity was found to have two dimensions: creativity orientation and creativity implementation. The total variance explained by these factors is $67.47 \%$ (KMO=0.93; Bartlett's Test of Sphericity $\left.X^{2}: 1419.35 ; \mathrm{df}: 78 ; \mathrm{p}<0.001\right)$. The Cronbach's alpha coefficients for the variables are presented in Table (1) below.

Table 1: Internal Consistency Coefficients of the Measures

\begin{tabular}{|l|c|}
\hline Scale & Cronbach Alpha \\
\hline Attitudinal Careerism & .69 \\
Behavioral Careerism & .71 \\
\hline Skill Utilization & .87 \\
Learning Opportunities & .86 \\
\hline Openness to Experience & .78 \\
Agreeableness & .58 \\
\hline Organizational Collectivism & .91 \\
\hline Trust in Supervisors & .92 \\
Trust in the Organization & .88 \\
\hline Creativity Orientation & .89 \\
Creativity Implementation & .87 \\
\hline
\end{tabular}

\subsection{Means, Standard Deviations, and Correlations among the Variables}

In Table (2), the means, standard deviations, and correlations among the variables have been reported. The relationships between the variables of the study were investigated by using Pearson product-moment correlation coefficients. Initial analyses were conducted to make certain that there is no violation of the assumptions of normality, linearity, and homoscedasticity.

As it can be noticed in the table below, the sub-dimensions of underemployment and organizational trust are significantly related. Skill utilization and trust in supervisors $(r=-.263, p<.001)$, skill utilization and trust in the organization $(r=-.291, p<.001)$, learning opportunities and trust in supervisors $(r=-.213, p<.001)$, and learning opportunities and trust in the organization $(r=-.186, p<.005)$ are negatively related and the correlation coefficients ranged from low to moderate. In terms of the relationship between underemployment and creativity, it was seen that there was a low negative correlation between learning opportunities and creativity orientation $(r=-.158, p<.005)$. No significant relationship was found between careerism and organizational trust. As to the careerism and creativity relationship, a low positive correlation between behavioral careerism and creativity implementation $(r=.165, p<.005)$ was found.

\subsection{Hypothesis Testing}

As seen in Table 2 above, all the sub-dimensions of underemployment and careerism are significantly correlated. There are positive and moderate correlations between skill utilization and attitudinal careerism $(r=.290, p<0.01)$, learning opportunities and attitudinal careerism $(r=.238, p<0.01)$, skill utilization and behavioral careerism $(r=.275, p<0.01)$, and learning opportunities and behavioral careerism $(r=.253, p<0.01)$. The positive correlations between underemployment and careerism reveal that Hypothesis 1 ("Underemployment will be positively related to careerism") is fully supported. 
For testing hypotheses 2, 3, 4, and 5, multiple regression analyses were conducted. Regarding Hypothesis 2 ("Underemployment will have a positive contribution to creativity."), it was found that both creativity orientation $\left(R^{2}=.073, F=6.054, p<.05\right)$ and creativity implementation $\left(\mathrm{R}^{2}=.051, \mathrm{~F}=4.083, \mathrm{p}<.05\right)$ were predicted significantly by the two underemployment dimensions. Although the two dimensions of underemployment significantly contributed to creativity dimensions, one was positive whereas the other was negative. Skill utilization was positivity related to creativity implementation $(\beta=.227 ; p=.009)$ and creativity orientation $(\beta=.241 ; p=.005)$. However, the learning opportunities dimension contributed negatively to creativity implementation $(\beta=-.180 ; p<.05)$ and creativity orientation $(\beta=-.256 ; p<.001)$. Therefore, Hypothesis 2 is partially supported.

The test for Hypothesis 3 ("Underemployment will have a negative contribution to organizational trust.") revealed that skill utilization significantly and negatively contributed to the two dimensions of trust in supervisors $\left(R^{2}=.069, F=11.467, p<.05\right)(B e t a=-$ $.263 ; p=.001)$ and trust in the organization $\left(R^{2}=.085, F=14.215, p<.05\right)$ (Beta=-.291; $\left.p=.000\right)$. However, no significant contribution was obtained for learning opportunities. Thus, Hypothesis 3 is partially supported.

Table 2: Means, Standard Deviations and Correlations between the Variables

\begin{tabular}{|c|c|c|c|c|c|c|c|c|c|c|c|c|c|c|}
\hline & Variable & Mean & SD & 1 & 2 & 3 & 4 & 5 & 6 & 7 & 8 & 9 & 10 & 11 \\
\hline 1 & $\begin{array}{l}\text { Creativity } \\
\text { orientation }\end{array}$ & 4,9 & 0,845 & 1 & & & & & & & & & & \\
\hline 2 & $\begin{array}{l}\text { Creativity } \\
\text { implementation }\end{array}$ & 4,6 & 0,838 &, $741^{* *}$ & 1 & & & & & & & & & \\
\hline 3 & $\begin{array}{l}\text { Trust in } \\
\text { supervisors }\end{array}$ & 4,5 & 1,054 &, $232^{* *}$ & 131 & 1 & & & & & & & & \\
\hline 4 & $\begin{array}{l}\text { Trust in the } \\
\text { organization }\end{array}$ & 4,2 & 1,229 &, $203^{*}$ &, $200^{*}$ &, $531^{* *}$ & 1 & & & & & & & \\
\hline 5 & $\begin{array}{l}\text { Organizational } \\
\text { collectivism }\end{array}$ & 3,9 & 1,145 &, $270^{* *}$ &, $248^{* *}$ &, $473^{* *}$ &, $665^{* *}$ & 1 & & & & & & \\
\hline 6 & Skill utilization & 3,6 & 1,161 & 136 & ,154 &,$- 263^{* *}$ &,$- 291^{* *}$ &,$- 165^{*}$ & 1 & & & & & \\
\hline 7 & $\begin{array}{l}\text { Learning } \\
\text { opportunities }\end{array}$ & 2,5 & 1,181 &,$- 158^{*}$ &,- 087 &,$- 213^{* *}$ &,$- 186^{*}$ &,$- 198^{*}$ & $409^{* *}$ & 1 & & & & \\
\hline 8 & $\begin{array}{l}\text { Attitudinal } \\
\text { careerism }\end{array}$ & 2,8 & 1,048 & ,013 &,- 024 &,- 075 &,- 147 &,- 126 &, $290^{* *}$ &, $238^{* *}$ & 1 & & & \\
\hline 9 & $\begin{array}{l}\text { Behavioral } \\
\text { careerism }\end{array}$ & 3,2 & 1,128 & ,093 &, $165^{*}$ &,- 051 &,- 026 &,- 013 &, $275^{* *}$ &, $253^{* *}$ &, $433^{* *}$ & 1 & & \\
\hline 10 & $\begin{array}{l}\text { Openness to } \\
\text { experience }\end{array}$ & 4,6 & 1,002 &, $505^{* *}$ &, $578^{* *}$ & 013 & $170^{*}$ &, $226^{* *}$ &, $220^{* *}$ &,- 003 & ,000 &, $227^{* *}$ & 1 & \\
\hline 11 & Agreeableness & 4,7 & 0,997 & ,394** & $265^{* *}$ & $158^{*}$ & $179^{*}$ & ,193* &,- 019 &,$- 215^{* *}$ &,- 119 & ,034 & $298^{* *}$ & 1 \\
\hline
\end{tabular}

* Correlation is significant at the 0.05 level (2-tailed).

** Correlation is significant at the 0.01 level (2-tailed).

For Hypothesis 4 ("Careerism will have a positive contribution to creativity."), the results showed that only the behavioral careerism dimension of careerism made a significant contribution $\left(R^{2}=.027, F=4.295, p<.05\right)$. Behavioral careerism (Beta=.165; $\mathrm{p}<.05)$ significantly predicted creativity implementation. Therefore, since attitudinal careerism made no significant contribution and behavioral careerism did not predict creativity orientation, Hypothesis 4 is partially supported.

The results for Hypothesis 5 ("Careerism will have a negative contribution to organizational trust.") indicated that attitudinal careerism and behavioral careerism were not significantly related with the two dimensions of trust. So, Hypothesis 5 is not supported.

For testing hypotheses, 6, 7, 8, and 9, hierarchical multiple regression analyses were conducted. As a first step, and to keep away from potential high multicollinearity with the interaction term, the variables were centered (Aiken \& West, 1991). The independent variable and the moderating variable were calculated by subtracting the mean values from the respondents' scores. The interaction term was computed by multiplying standardized scores of variables.

The findings indicated that Hypothesis 6 ("Organizational collectivism will strengthen the positive relationship between underemployment and creativity"), Hypothesis 7 ("Openness to experience will strengthen the positive relationship between careerism and creativity."), and Hypothesis 8 ("Organizational collectivism will weaken the negative relationship between 
underemployment and organizational trust") were not supported. However, partial support was obtained for Hypothesis 9 ("Agreeableness will weaken the negative relationship between careerism and organizational trust."). As seen in Table 3, the model was significant for the interaction of behavioral careerism and agreeableness (Beta $=-.159 ; t=-1.998 ; p<0.05)$, and the explanatory power at step 3 had increased $\left(R^{2}=.053\right)$.

Table 3: The Moderating Role of Agreeableness on the Relationship between Behavioral Careerism and Trust in Supervisors

\begin{tabular}{|c|c|c|c|c|c|c|c|}
\hline Variables & B & Beta & $\mathbf{R}^{2}$ & Adjusted $\mathrm{R}^{2}$ & $\begin{array}{c}\mathbf{R}^{2} \\
\text { change }\end{array}$ & $\mathbf{F}$ & $\mathbf{P}$ \\
\hline Step 1 & -.053 & -.051 & .003 & -.004 & .003 & $\begin{array}{c}.396 \\
t \\
-.629 \\
\end{array}$ & .530 \\
\hline $\begin{array}{l}\text { Step } 2 \\
\text { Behavioral Careerism } \\
\text { Agreeableness }\end{array}$ & $\begin{array}{l}-.059 \\
.168\end{array}$ & $\begin{array}{c}-.056 \\
.160\end{array}$ & .028 & .015 & .025 & $\begin{array}{l}2.209 \\
\mathbf{t} \\
-.703 \\
2.003\end{array}$ & $\begin{array}{l}.013 \\
.483 \\
.047\end{array}$ \\
\hline $\begin{array}{l}\text { Step } 3 \\
\text { Behavioral Careerism } \\
\text { Agreeableness } \\
\text { Behavioral Careerism* } \\
\text { Agreeableness }\end{array}$ & $\begin{array}{l}-.040 \\
.161 \\
-.171\end{array}$ & $\begin{array}{l}-.038 \\
.153 \\
-.159\end{array}$ & .053 & .034 & .025 & $\begin{array}{c}2.832 \\
\mathbf{t} \\
-.472 \\
1.934 \\
-1.998 \\
\end{array}$ & $\begin{array}{l}.040 \\
.637 \\
.055 \\
.048\end{array}$ \\
\hline
\end{tabular}

Since the interaction was significant, two-way interaction effects for standardized variables were plotted as it can be seen in Figure 2, and the Probing Procedure suggested by Aiken and West (1991) was conducted to make a final decision regarding the confirmation of the result presented in Table 3.

As it can be seen in the below figure, agreeableness weakens the negative relationship between behavioral careerism and trust in supervisors. That is, behavioral careerism leads to a lower decrease in trust in supervisors when agreeableness is high.

Figure 2: The Interaction of Behavioral Careerism and Agreeableness in terms of Their Effect on Trust in Supervisors 


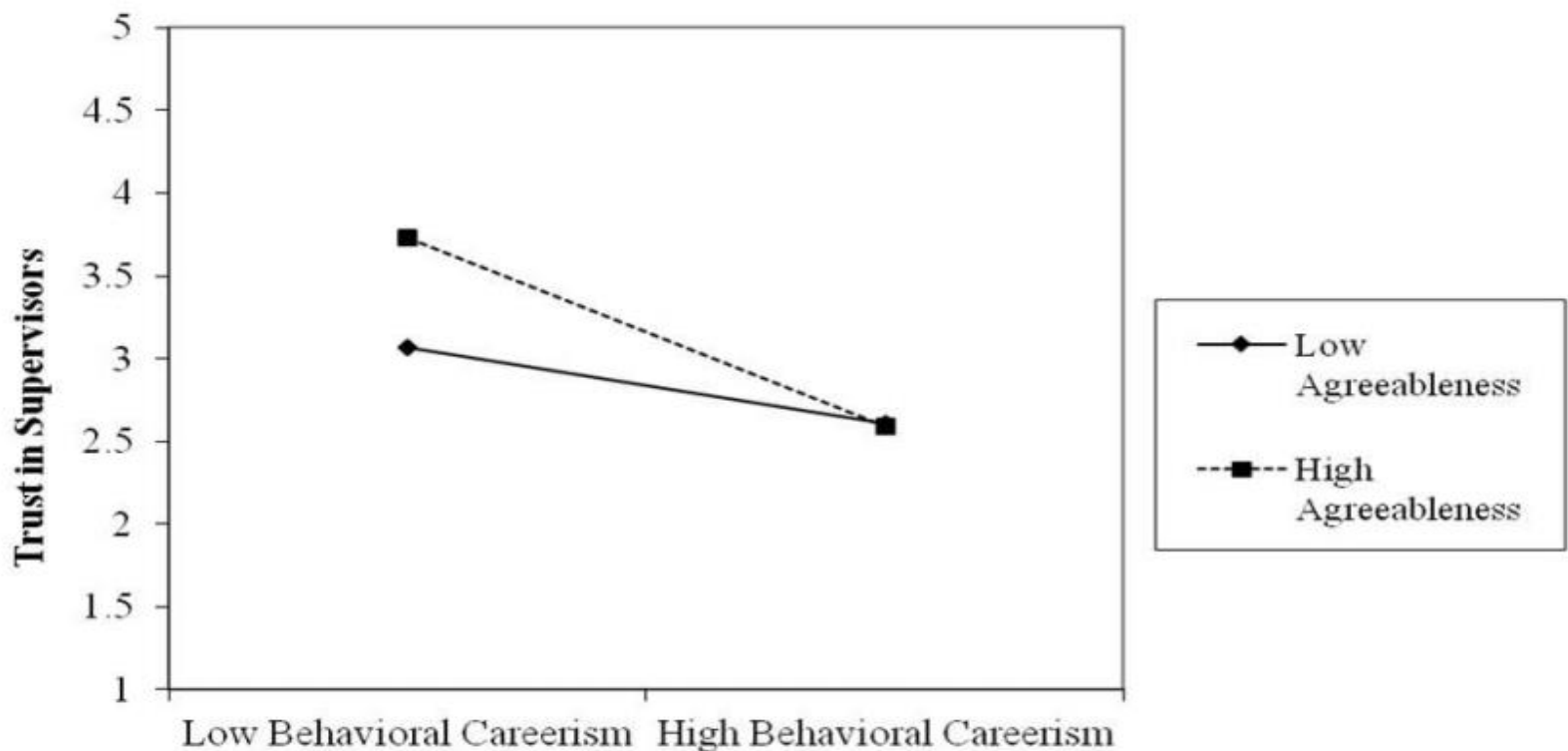

\section{CONCLUSION AND DISCUSSION}

As it was stated earlier, this study aimed to look into the positive side of two seemingly negative variables, which are underemployment and careerism. It sought to explore the impacts of these variables on creativity and organizational trust. The study has put all the assumed relationships within the personality and environmental context. Therefore, the study argued that some personality traits (e.g. openness to experience and agreeableness) and the type of culture in the workplace (collectivism) could moderate the relationships among the mentioned variables. In the coming paragraphs, the results of the study will be discussed in light of the previous studies.

In the present study, the two dimensions of underemployment which are skill utilization and learning opportunities were found to have a positive relationship with the two dimensions of careerism (attitudinal and behavioral). Thus, Hypothesis 1 has been supported. The findings are in line with the previous studies as it has been mentioned earlier. An employee who is not able to fully utilize his/her skills, experiences a sense of psychological emptiness and self-contempt or loss of self-esteem. Such a person will start thinking about finding a job where he/she can be able to achieve a sort of self-assertion. The same assumption can be stated about an employee who does not have the opportunities to learn and improve himself/herself in the organization that he/she is working for. He/she would be likely to lose psychological attachment to it because of the feeling that the organization is not fulfilling the employee's psychological need for self-enhancement and development, which makes the person to gradually develop careerist attitudes. However, the question that arises is that, do all employees who experience some or all types of underemployment develop careerism orientation? At least, the studies which have been found have not yielded consistent results (Cockroft, 2011). There are very few studies which attempted to unlock and lighten the relationship between these two variables. There seems to be more need for conceptual and empirical studies that would produce clear information about these constructs.

The second hypothesis was about the positive contribution of underemployment to creativity. The results have revealed that all the relationships between underemployment and creativity dimensions were significant. However, not all of them were positive as it was expected. Skill utilization was found to be positively related with the two dimensions of creativity (creativity orientation and creativity implementation); whereas learning opportunities were found to be negatively related to the two earlier mentioned creativity dimensions. Regarding the positive relationship of skill utilization with creativity, the finding is in line with the results of a study conducted by Lin, Law, and Zhou (2017). Lin et al. (2017) attempted to explore the positive contributions of underemployment to creativity and organizational citizenship behavior. Lin et al. (2017) have found that underemployment could be a positive 
element in the workplace, and the underemployed employee could be a creative person if the organization fulfills some conditions. According to them, objective underemployment affects subjective underemployment, which in turn affects employees' images about their jobs. Therefore, the organizational environment and employees' personality characteristics help them to develop a positive image in their eyes and others' eyes about their jobs. When employees perceive objective underemployment positively, they automatically move to a new stage called task crafting, the key element of which is creativity. For the underemployed individuals, task crafting becomes a means of ensuring a better fit with their preferences and competencies and asserting a positive self-image which leads them to be creative in their domains. Consequently, the positive relationship between skill utilization and the two dimensions of creativity could be explained based on Lin et al.'s (2017) view which has been mentioned in the previous lines. Besides, it is possible that employees may use their already existing potentials to demonstrate creativity. However, those who have experienced underemployment in terms of learning opportunities were found to be less likely to be creative. The improbability of acquiring new masteries seems to impede creativity. Accordingly, and based on Zhou and George's (2001) work, most probably these employees might be reacting passively to their underemployment conditions through neglect (withdrawal behaviors such as applying fewer efforts) or loyalty (accepting the negative conditions without trying to change anything).

The third hypothesis asserted that underemployment will have a negative contribution to organizational trust. The results of the present study revealed that skill utilization significantly and negatively contributed to the two dimensions of organizational trust. However, the contribution of learning opportunities to the two dimensions of trust was not significant. The employees who experience underemployment in terms of skill utilization might remain in the same organization due to continuous commitment, however, this may happen at the expense of distrust between the employees and their supervisors in particular and the organization in general. On the other hand, the insignificant relationship between the learning opportunities dimension of underemployment and the two dimensions of organizational trust, leads us to question the nature of learning opportunities, whether it is more related to job satisfaction or it is about underemployment as Feldman (2000) has suggested in his work. This claim might be put forward because it seems that the employee who does not have opportunities to get further training to improve himself/herself, most probably feels dissatisfied rather than feeling underemployed. Therefore, such employees may feel dissatisfied about the job and the organization that they work for, without developing a problem of trust.

The positive contribution of careerism to creativity was the fourth hypothesis of the present study. The findings showed that the hypothesis was partially supported. It was found that behavioral careerism had a positive contribution to creativity implementation. This hypothesis was formulated based on the theory that careerism has two dimensions, one being positive and the other being negative. The positive side of careerism stands on Rousseau's (1990) point of view. She argued that careerism is a concept which has so much overlapped with two concepts, which are: first, protean career, which reflects the person who is self-directed and internally driven by his convictions; and second, boundary less career, which reflects the person who sees himself and his career as being independent of organizational boundaries. The self-sufficient individual may work in different organizations to do different jobs since he/she has acquired many skills and experiences (Adams, et al., 2012; Arthur and Rousseau, 1996; Briscoe, et al., 2006). This dimension of careerism which is called behavioral careerism may lead employees to develop new approaches and provide innovative solutions to problems.

The fifth hypothesis of this study proposed that careerism will have a negative contribution to organizational trust. The results showed that there is no significant contribution of any dimension of careerism to organizational trust dimensions. Researchers point out that organizational trust is a reciprocal relationship between two parties. This reciprocal relationship is the crucial element in any psychological contract, and the trust is placed at the core of the psychological contract breach (Robinson and Morrison, 2000). Based on Sullivan and Baruch (2009), however, it may be stated that, in the new era, a tendency of a more transactional psychological contract rather than a relational one is observed. That is, the relationship between the employee and the employer is based on legal rights and reciprocal benefits rather than on the mutual trust only. These changes in employment relationships have pushed employees to develop new attitudes and coping strategies (Adams et al., 2012). The acceptance of exchange-based interactions as a norm may lead to careerist intentions that are irrelevant in terms of trustful attitudes. The findings of this research and the contradicting results of Crawshaw and Brodbeck's (2011) study seem to call for more detailed studies concerning the nature of the relationship between careerism and organizational trust. 
For hypotheses 6,7 , and 8 no significant results were obtained for the moderating roles of organizational collectivism and openness to experience variables.

For the ninth hypothesis, however, partial support was obtained. It was expected that agreeableness will weaken the negative relationship between careerism and organizational trust. The hypothesis was partially supported since the results have shown that agreeableness moderates the relationship between behavioral careerism and trust in supervisors only. Although the relationship between behavioral careerism and trust in supervisors was found to be negative but insignificant, the moderating effect of agreeableness on this relationship turned out to be significant. Previous research provides support for this result. Many studies have confirmed the positive relationship between agreeableness and trust (Dinesen, Nørgaard, and Klemmensen, 2014; Freitag and Bauer, 2016; Hiraishi, Yamagata, Shikishima, and Ando, 2008; Mondak and Halperin, 2008; Oskarsson et al., 2012; Weinschenk and Dawes, 2019). Besides, an employee who is behaviorally careerism-oriented has positive psychological and behavioral characteristics (e.g., self-confidence, tolerating uncertainty, enthusiasm, and determination). Therefore, it may be assumed that when an employee demonstrates careerism in the positive sense and has an agreeable type of personality, he/she most probably will have trust in supervisors and they will respond similarly. The moderating effect of agreeableness was only observed for trust in supervisors but not for trust in the organization. A study conducted by Tan and Tan (2000) revealed that proximal variables such as the ability, benevolence, and integrity which were embodied by a supervisor and as perceived by his or her employees have a positive effect on employees' trust in supervisors. However, global variables such as perceived organizational support and justice were associated with trust in the organization rather than trust in supervisors. Thus, it may be concluded that, in general, trust in supervisor is predicted by individual variables.

\section{LIMITATIONS OF THE STUDY}

Some limitations have to be mentioned in the present study. These are mainly related to the methodology of the research. The first point to be stated is the utilization of self-report questionnaires as data collection tools. The disadvantages of using such tools are well-known among researchers. Generally, the use of self-report questionnaires may raise the possibility of common method variance. For instance, a respondent may fall in social desirability bias, which is a socio-psychological state that leads a person to respond in a socially acceptable way. This may happen especially if the answer could affect his/her future career in the organization (e.g., such as revealing that he/she is careerism-oriented or expressing the intention to leave the organization sooner or later). Besides, he/she may fall in response bias which is a psychological state that directs the person to respond in a certain way regardless of the question.

Secondly, another problem related to the method section may be the clarity of the items which is influenced by cultural differences, translation, or the rephrasing of the items. Some of the questionnaires were translated into Turkish Language and were tested for their reliability and validity in the Turkish setting by the authors of the test (e.g., organizational collectivism) whereas others were translated by other researchers (e.g., creativity, organizational trust), or by the author of this study (e.g., underemployment and careerism). Since the measurement scales were not developed in the Turkish context, the translated instruments might have affected the comprehensibleness of the items for the respondents via cultural differences or linguistically ambiguous content.

Thirdly, the limitations of methodology concern the sampling method and the sampling size. The convenience sampling method has been utilized in the present study which means that the results cannot be generalized to the entire population. Although the sample size consisting of 156 participants is acceptable, some differences in terms of the results obtained in various studies may be attributable to larger sample sizes used in them.

Finally, an issue related to the nature of the sample exists. The participants of this study were from different work sectors (e.g., service, industry, etc.) which might be a cause affecting some results of the study. Since some variables of the study are domaingeneral oriented, such as creativity, the manifestation of the construct may vary among different work fields. The exposure of creativity in a business field may not be the same as it is in a service field. Therefore, the heterogeneous nature of the sample may have influenced the findings.

\section{SUGGESTIONS FOR FUTURE RESEARCH}


First of all, what can be concluded from the theoretical background of the conceptualization of careerism is that there is a clear disagreement between Rousseau (1990) and Feldman and Weitz (1991) in terms of the conceptualization of careerism. A closer look at the researchers' conceptualizations makes a reader feel that each one is describing careerism differently. Rousseau's (1990) conceptualization of careerism seems to fit an employee who works in an organization to which he/she is not attached psychologically and has the ability and the will to leave it. Accordingly, the employee tends to make his/her current job as a stepping stone to another more satisfying job. On the other hand, Feldman and Weitz's (1991) conceptualization seems to imply that the employee is not satisfied with the job he/she is doing, however, is not able to leave the job. That is why the employee may start using non-performance based means in the pursuit of career growth. Therefore, the psychological state of the employee in Rousseau's (1990) conceptualization is positive and enterprising in contrast to that of Feldman and Weitz's (1991) which is negative and passive. These two views of careerism may affect the course of any study in quite a different way. Therefore, it is recommended for future research to study these two conceptualizations deeply to clarify the nature of the construct.

Second, in the present study, only openness to experience and agreeableness as personality traits have been set forth as variables to moderate the relationship between careerism and creativity; and careerism and organizational trust. Since other traits were not tested, it is strongly suggested for future research to study the moderation effects of different personality traits.

Third, only individual variables (openness to experience and agreeableness) were used for investigating the moderating effects on the relationship between careerism and creativity; and careerism and organizational trust. However, and based on Amabile's (1983) Componential Theory of Creativity, researchers have emphasized the fact that personal and contextual characteristics contribute jointly to creativity (Oldham and Cumming, 1996). Therefore, it is recommended for future research to study the effects of contextual variables such as organizational culture, leadership styles, communication network, and the like as well.

Fourth, as it was mentioned earlier in the limitations section, the participants of this study were from different work sectors (e.g., service, industry, etc.), which seems to be a potential cause for influencing the findings of the study. As domain-general oriented constructs such as creativity may be expressed differently in distinct work areas, it is suggested to explore the relationships of the variables of the current research in specific work domains for the generalizability of the results. Besides, a larger sample size would further increase the generalizability of the study findings.

Lastly, in the discussion section, a note related to Amabile's (1983) Creativity Theory was emphasized. The Componential Theory of Creativity has been developed in an era which was characterized according to Sullivan and Baruch (2009) as the period of traditional career model. This model, in general, maintains an exchangeable loyalty between the employer and the employee, a type of psychological contract. However, the present study represented an attempt of studying creativity and its relationship with careerism and underemployment, in the novel era of career system which is based on a transactional contract. The new contract is a result of fundamental changes in terms of the work environment and personal career attitudes. These changes prompt us to question the compatibility of the theory with the current situation and to ask if there is a need to re-conceptualize the theory to adapt the present change. Therefore, it is recommended for future research to test Amabile's (1983) Creativity Theory in this new personal and contextual environment.

\section{THEORETICAL AND PRACTICAL CONTRIBUTIONS OF THE STUDY}

The current study could be beneficial in several aspects; which will be summarized in the following points:

1- The study offers a comprehensive understanding of the issues of underemployment and careerism from an organizational behavior perspective as distinct from an economic point of view. This approach may help researchers and practitioners to search for different ways to clarify and treat underemployment and careerism.

2- The study highlights that focusing only on the negative sides of underemployment and careerism concepts may be an incomplete approach. The present study revealed that some dimensions of underemployment and careerism contributed positively to creativity. Besides, it was seen that some dimensions of these constructs did not display significant relationships with organizational trust. Thus, the current research presents cues for exploring the beneficial outcomes of underemployment and careerism.

3- The study also contributes theoretically and practically in terms of learning how personality traits affect employee trust. The finding that agreeableness has a moderating role in the relationship between behavioral careerism and trust in supervisors indicates that an agreeable employee displaying careerist orientations may put forward a trusting attitude toward the supervisor. Therefore, in hiring selections agreeable employees may be preferred when careerist behaviors are dominant. 


\section{REFERENCES}

Adams, J. W., Srivastava, A., Herriot, P. \& Patterson, F. (2012). Careerist Orientation and Organizational Citizenship Behavior in Expatriates and Non-Expatriates. Journal of Career Development, 40(6), 469-489.

Aiken, L. S., \& West, S. G. (1991). Multiple Regression: Testing and Interpreting Interactions. Newbury Park, CA: Sage Publications.

Amabile, T. M. (1983). The Social Psychology of Creativity. New York: Springer Verlag.

Amabile, T. M., Conti, R., Coon, H., Lazenby, J., \& Herron, M. (1996). Assessing the Work Environment for Creativity. Academy of Management Journal, 39, 1154-1184.

Amabile, T. M. (1998). A Model of Creativity and Innovation in Organizations. Research in Organizational Behavior, 10, $123-167$.

Arthur, M. B., \& Rousseau, D. M. (1996). The Boundaryless Career: A New Employment Principle for a New Organizational Era. New York, NY: Oxford University Press.

Batey, M., \& Furnham, A. (2006). Creativity, Intelligence, and Personality: A Critical Review of the Scattered Literature. Genetic, Social, and General Psychology Monographs, 132, 355-429.

Beck, U. (1999). World Risk Society. Cambridge: Polity Press.

Bolino, M. C., \& Feldman, D. C. (2000). The Antecedents and Consequences of Underemployment among Expatriates. Journal of Organizational Behavior, 21(8), 889-911.

Briscoe, J. P., Hall, D. T., \& DeMuth, R. L. F. (2006). Protean and Boundaryless Careers: An Empirical Exploration. Journal of Vocational Behavior, $69,30-47$.

Caliendo, M., Fossen, F., \& Kritikos, A. (2014). Personality Characteristics and the Decision to Become and Stay Self-Employed. Small Business Economics, 42(4), 787- 814.

Chan, R. H. K. (2012). Competence, Trust, Job-related Risks and Their Management: The Case of Hong Kong. Asian Journal of Political Science, 20(3), 267-283.

Chay, Y. W., \& Aryee, S. (1999). Potential Moderating Influence of Career Growth Opportunities on Careerist Orientation and Work Attitudes: Evidence of the Protean Career Era in Singapore. Journal of Organizational Behavior, 20(5), 613- 623.

Cockroft, K. B. (2011). The Relationship between Underemployment and Job Attitudes of New Zealand Graduates. (Thesis, Master of Applied Psychology). University of Waikato, Hamilton, New Zealand. Retrieved from https://hdl.handle.net/10289/5337.

Crawshaw, J. R., \& Brodbeck, F. C. (2011). Justice and Trust as Antecedents of Careerist Orientation. Personnel Review, 40, $106-125$.

Dinesen, P. T., Nørgaard, A. S., \& Klemmensen, R. (2014). The Civic Personality: Personality and Democratic Citizenship. Political Studies, 62, 134152.

Feist, G.J. (1998). A Meta-analysis of Personality in Scientific and Artistic Creativity. Personality and Social Psychology Review, 2(4), 290-309.

Feldman, D. C. (1996). The Nature, Antecedents and Consequences of Underemployment. Journal of Management, 22(3), 385-407.

Feldman, D. C., \& Weitz, B. A. (1991). From the Invisible Hand to the Glad-hand: Understanding a Careerist Orientation to Work. Human Resource Management, 30(2), 237-257.

Feldman, D. C., Leana, C. R., \& Bolino, M. C. (2002). Underemployment and Relative Deprivation among Re-employed Executives. Journal of Occupational and Organizational Psychology, 75(4), 453-471.

Feldman, M. S. (2000). Organizational Routines as a Source of Continuous Change. Organization Science, 11, 611-629.

Freitag, M., \& Bauer, P. C. (2016). Personality Traits and the Propensity to Trust Friends and Strangers. The Social Science Journal, 53(4), 467-476.

Gosling, S. D., Rentfrow, P. J., \& Swann, W. B. (2003). A Very Brief Measure of the Big-Five Personality Domains. Journal of Research in Personality, 37, 504-528.

Greenhaus, J. H., Callanan, G. A., \& DiRenzo, M. (2008). A Boundaryless Perspective on Careers. In J. Barling (Ed.), Handbook of Organizational Behavior: 277-299. Thousand Oaks, CA: Sage. 
Hiraishi, K., Yamagata, S., Shikishima, C., \& Ando, J. (2008). Maintenance of Genetic Variation in Personality through Control of Mental Mechanisms: A Test of Trust, Extraversion, and Agreeableness. Evolution and Human Behavior, 29, 79-85.

Lin, B., Law, K., \& Zhou, J. (2017). Why Is Underemployment Related to Creativity and OCB? A Task Crafting Explanation of the Curvilinear Moderated Relations. Academy of Management Journal, 60(1), 156-177.

Loewenthal, K. M. (2001). An Introduction to Psychological Tests and Scales (2nd ed). Hove, East Sussex: Psychology Press Limited.

Luhmann, N. (1979). Trust and Power. New York: John Wiley.

MacKinnon, D. W. (1962). The Nature and Nurture of Creative Talent. American Psychologist, 17, 484-495 [University of California, Berkeley, CA].

Meyer, J. P., Allen, N. J., \& Smith, C. (1993). Commitment to Organizations and Occupations: Extension and Test of a Three-component Conceptualization. Journal of Applied Psychology, 78, 538-551.

Mondak, J., \& Halperin, K. (2008). A Framework for the Study of Personality and Political Behavior. British Journal of Political Science, $38,335-362$.

Nyhan, R. C., \& Marlowe, H. A. (1997). Development and Psychometric Properties of the Organizational Trust Inventory. Evaluation Review, 21(5), 614-635.

Oldham, G. R., \& Cummings, A. (1996). Employee Creativity: Personal and Contextual Factors at Work. Academy of Management Journal, 39(3), 607-634.

Oskarsson, S., Dawes, C., Johannesson, M., \& Magnusson, P. (2012). The Genetic Origins of the Relationship between Psychological Trust and Social Trust. Twin Research and Human Genetics, 15, 21-33.

Robert, C., \& Wasti, S. A. (2002). Organizational Individualism and Collectivism: Theoretical Development and an Empirical Test of a Measure. Journal of Management, 28(4), 544-566.

Robinson, S. L., \& Morrison, E. W. (2000). The Development of Psychological Contract Breach and Violation: A Longitudinal Study. Journal of Organizational Behavior, 21(5), 525-546.

Rousseau, D. M. (1990). New Hire Perceptions of Their Own and Their Employer's Obligations: A Study of Psychological Contracts. Journal of Organizational Behavior, 11(5), 389- 400.

Rousseau, D. M. (2000). Psychological Contract Inventory, Technical Report \#3. Pittsburgh, PA: Heinz School of Public Policy, Carnegie Mellon University.

Sullivan, S. E., \& Baruch, Y. (2009). Advances in Career Theory and Research: A Critical Review and Agenda for Future Exploration. Journal of Management, 35, 1542-1571.

Tan, H., \& Tan, C. S. (2000). Towards the Differentiation of Trust in Supervisor and Trust in Organization. Genetic, Social and General Psychology Monographs, 126(2), 241-260.

Uslaner, E. M. (2002). The Moral Foundations of Trust. Cambridge, United Kingdom: Cambridge University Press.

Weinschenk, A. C., \& Dawes, C. T. (2019). The Genetic and Psychological Underpinnings of Generalized Social Trust. Journal of Trust Research, 9(1), 47-65.

Zhou, J., \& George, J. M. (2001). When Job Dissatisfaction Leads to Creativity: Encouraging the Expression of Voice. Academy of Management Journal, 44(4), 682-696.

Zhou, J., \& George, J. M. (2003). Awakening Employee Creativity: The Role of Leader Emotional Intelligence. The Leadership Quarterly, 14(4), 545568. 